\title{
STRATEGI PENANGANAN RISIKO OPERASIONAL PEMASARAN PRODUK TEH CELUP HIJAU WALINI PADA INDUSTRI HILIR TEH PT PERKEBUNAN NUSANTARA VIII, BANDUNG, JAWA BARAT
}

\author{
Idzhar Jaya Nugraha, Akhmad Riyadi Wastra* dan Lilis Imamah Ichdayati
}

\begin{abstract}
ABSTRAK
Teh merupakan produk unggulan Indonesia yang telah diakui di seluruh dunia. Indonesia adalah penghasil teh terbaik ketujuh yang memiliki pasar internasional potential.Therefore Tea Indonesia diperkirakan akan memanfaatkan peluang yang ada dari industri hilir teh. Salah satu perusahaan perkebunan lain milik yang memiliki industri hilir teh PT Perkebunan Nusantara VIII. Teh Walini ini adalah satu produk merek terkenal untuk perusahaan ini. Industri hilir pengembangan teh PTPN VIII dihadapkan dengan belum mencapai penjualan yang diharapkan. Jumlah pemasaran operasional biaya dan penjualan ditunjukkan dari risiko operasional. Tujuan dari penelitian ini adalah penanganan strategi pemasaran risiko operasional Walini Hijau produk kantong teh di industri hilir teh PTPN VIII. identifikasi risiko adalah langkah pertama untuk mengetahui masalah pemasaran operasional di industri hilir teh PTPN VIII. Dengan menggunakan Z-Score dan Value at Risk (VAR) Metode, itu akan menunjukkan hasil probabilitas dan dampak pemasaran risiko operasional. Preventif dan strategi mitigasi dapat menangani perusahaan ini untuk pertumbuhan up penjualan diharapkan.
\end{abstract}

Kata kunci: industri hilir teh, risiko operasional pemasaran, z-skor, VaR

\begin{abstract}
Tea is an Indonesian excellent product that has been recognized worldwide. Indonesia is the seventh best tea producer which have international market potential.Therefore Tea Indonesia is expected to take advantage on existing opportunities from downstream industry of tea. The one of stated-owned plantation company who have downstream industry of tea is PT Perkebunan Nusantara VIII. Walini's tea is a one famous brand product for this company. The development downstream industry of tea PTPN VIII is faced with yet achieved the expected sales. Amount of cost operational marketing and sales are indicated of operational risk. The objective of this study is strategy handling of marketing operational risk Walini Green tea bag product in downstream industry of tea PTPN VIII. Identification risk is first step to know the problem of marketing operational in downstream industry of tea PTPN VIII. By using Z-Score and Value at Risk (VAR) metode, it be showed
\end{abstract}


the result of probability and impact of marketing operational risk. Preventif and mitigation strategy can be handling this company to growth up the expected sales.

Keywords : downstream industry of tea, marketing operational risk, z-score, VaR

\section{PENDAHULUAN}

Teh merupakan produk unggulan Indonesia yang sudah diakui dunia, karena tingginya kandungan katekin (sebagai antioksidan) dibandingkan dengan teh negara lain. Data International Tea Comitte dalam Sinar Tani (2015:5) disebutkan bahwa Indonesia masuk dalam tujuh besar sebagai produsen teh terbaik di dunia setelah Tiongkok, India, Kenya, Srilanka, Turki, dan Vietnam. Menurut Ditjen Perkebunan dalam Sinar Tani (2015:5) dijelaskan bahwa posisi tujuh besar ini didukung dengan tingkat produksi teh Indonesia mencapai 145.460 ton atau 3,2\% dari produksi teh dunia sebesar 4,6 juta ton.

Potensi perkebunan teh yang dimiliki Indonesia dapat dimanfaatkan dalam proses hilirisasi pengolahan teh untuk memperluas pangsa pasar teh di Indonesia. Selama ini diketahui banyak teh berkualitas langsung di ekspor tanpa ada proses pengolahan lebih lanjut. Salah satu perusahaan perkebunan milik BUMN yaitu PT Perkebunan Nusantara VIII atau PTPN VIII, membuka suatu unit bisnis yang memiliki blending khusus dengan pabrik kemasan teh celup dan curah yang dikenal dengan nama Industri Hilir Teh PTPN VIII. Salah satu merek terkenal yang di produksi IHT PTPN VIII adalah teh merek Walini baik berupa teh seduh(looseleaf tea) maupun dengan kemasan (bagged tea). IHT PTPN VIII sendiri memiliki beberapa keunggulan, selain memiliki kebun sendiri, teh yang dihasilkan oleh IHT PTPN VIII, dibuat dari bahan baku teh berkualitas ekspor yang diolah tanpa campuran bahan apapun dan dikemas secara profesional.

Pada tahun 2012 dan 2013 penjualan IHT PTPN VIII tidak mencapai Rancangan Kerja dan Anggaran Perusahaan (RKAP), ketidaksesuaian tersebut dapat terlihat pada Tabel 1 :

\begin{tabular}{|l|r|r|r|r|r|r|}
\hline \multirow{2}{*}{$\begin{array}{c}\text { Uraian (Dalam Juta } \\
\text { Rupiah) }\end{array}$} & \multicolumn{2}{|c|}{2012} & \multicolumn{2}{c|}{2013} & \multicolumn{2}{c|}{ \% Perubahan } \\
\cline { 2 - 8 } & Realisasi & \multicolumn{1}{c|}{ RKAP } & Realisasi & \multicolumn{1}{c|}{ RKAP } & Realisasi & RKAP \\
\hline Penjualan & 31.487 & 39.990 & 32.363 & 44.161 & 2,8 & $(5,5)$ \\
\hline $\begin{array}{l}\text { Harga Pokok } \\
\text { Penjualan }\end{array}$ & 26.290 & 32.074 & 25.606 & 32.855 & 25 & 2,4 \\
\hline Laba Kotor & 5.197 & 10.348 & 6.756 & 11.305 & 30 & 0,2 \\
\hline Biaya Usaha & 9.018 & 9.650 & 9.858 & 10.571 & 17,2 & 9,5 \\
\hline Laba Usaha & $(3.821)$ & - & $(3.102)$ & 735 & 18,8 & - \\
\hline $\begin{array}{l}\text { Pend/(Biaya) Non } \\
\text { Usaha }\end{array}$ & $(161)$ & $(220,6)$ & $(142)$ & $(227)$ & 41 & 10,4 \\
\hline Laba Sebelum Pajak & $(3.982)$ & - & $(3.243)$ & 508 & $(18.5)$ & - \\
\hline
\end{tabular}

Sumber : Annual Report PTPN VIII, 
Pada tahun 2012 biaya usaha yang dikeluarkan sebesar Rp 9 Miliyar dan meningkat pada tahun 2013 sebesar Rp 9,8 Miliyar. Persentase perubahan biaya usaha pada tahun 2012 ke 2013 meningkat sebesar 17,2 $\%$. Besarnya biaya usaha yang dikeluarkan belum dapat ditutupi dari laba kotor yang dihasilkan pada tahun 2012 dan 2013 menyebabkan perusahaan mengalami kerugian. Kerugian yang diderita pada tahun 2013 mencapai Rp 3,2 Miliyar, sementara target pencapaian RKAP sebesar Rp 508 Juta. Kerugian yang terjadi pada tahun 2012 dan 2013 dikarenakan meningkatnya biaya usaha yang disebabkan naiknya biaya operasional pemasaran dan penjualan. Sementara Keterserapan pasar dari produk industri hilir teh masih belum optimal, hal ini dikarenakan tidaktercapainya volume penjualan dari produk-produk teh celup, teh seduh dan teh instan.

Penurunan volume penjualan juga terjadi teh celup hijau Walini dari tahun 2013 ke 2014. Penurunan penjualan pada tahun 2013 ke 2014 terlihat di bulan Desember tahun 2013 dimana daya serap produk mencapai $456.60 \mathrm{Kg}$, sementara tahun 2014 hanya mencapai $390,65 \mathrm{Kg}$. Penurunan pada penjualan teh celup hijau Walini merupakan penurunan terbesar diantara produk teh celup Walini lainnya, sehingga menyebabkan sisa produk yang tidak terjual mengalami penumpukan di gudang, yang pada akhirnya mempengaruhi penerimaan yang berfluktuatif.

Keberadaan manajemen risiko operasional pemasaran merupakan antisipasi atas semakin kompleksnya aktivitas perusahaan yang dipicu oleh perkembangan permintaan konsumen terhadap teh yang bervariasi. Semakin banyaknya kegagalan dalam aktivitas pemasaran, membuat IHT PTPN VIII harus mengantisipasinya melalui risiko operasional, sehingga kinerja pemasaran semakin baik. Oleh karena itu, penelitian yang berjudul "Strategi Penanganan Risiko Operasional Pemasaran Produk Teh Celup Hijau Walini Pada Industri Hilir Teh PT Perkebunan Nusantara VIII, Bandung, Jawa Barat" dapat menemukan solusi dalam meningkatkan pemasaran industri hilir teh.

Berdasarkan latar belakang di atas maka penelitian ini bertujuan untuk : (1) mengidentifikasi sumbersumber risiko operasional yang terjadi pada pemasaran teh celup hijau Walini beserta sumber-sumber risikonya di IHT PTPN VIII. (2) menganalisis pengukuran risiko operasional pemasaran dan memetakan sumber risiko yang terjadi pada produk teh celup hijau Walini di IHT PTPN VIII. (3) menentukan strategi penanganan risiko operasional pemasaran yang sebaiknya dilakukan pada produk teh celup hijau Walini di IHT PTPN VIII.

\section{TINJAUAN PUSTAKA}

\section{Konsep Risiko dalam Al-Qur'an}

Perspektif Islam dalam penanganan risiko dapat dikaji dari kisah Yusuf dalam mentakwilkan mimpi pada raja masa itu. Kisah ini termaktub dalam Al-Qur'an sebagai berikut :

"Raja berkata (kepada orang-orang terkemuka dari kaumnya): 'Sesungguhnya aku bermimpi melihat tujuh ekor sapi betina yang gemukgemuk di makan oleh tujuh ekor sapi sapi betina yang kurus-kurus dan tujuh bulir (gandum) yang hijau dan tujuh bulir lainnya yang kering.' Hai orang-orang yang terkemuka: 
'Terangkanlah kepadaku tentang ta'bir mimpiku itu jika kamu dapat mena'birkan mimpi." (QS. Yusuf: 43). Ibnul Asir Al-Jazari dalam AlQuran Cordoba (2015:111-1112) menafsirkan bahwa Nabi Yusuf memahami tujuh ekor sapi tahun masa pertanian. Boleh jadi sapi digunakan sebagai pembajak, kegemukan sapi lambang kesuburan, sedang sapi kurus adalah masa sulit di bidang pertanian, yakni paceklik. Bulir-bulir gandum sama pangan yang tersedia. Setiap bulir sama dengan setahun, demikian juga sebaliknya. Dari kisah tersebut dalam tafsir Al-Misbah karangan M. Quraish Shihab dalam Yogie (2015:1) dijelaskan bahwa pada tujuh tahun kedua akan timbul kekeringan yang dahsyat. Ini merupakan suatu risiko yang menimpa negeri Yusuf. Namun dengan adanya mimpi sang raja yang kemudian ditakwilkan oleh Yusuf maka kemudian Yusuf telah melakukan pengukuran dan pengendalian atas risiko yang akan terjadi pada tujuh tahun kedua tersebut. Pengendalian risiko dilakukan Yusuf dengan cara menyarankan kepada rakyat seluruh negeri untuk menyimpan sebagian hasil panennya pada panen tahun pertama demi menghadapi paceklik tujuh tahun berikutnya.

Dengan demikian maka terhindarlah bahaya kelaparan yang mengancam negeri Nabi Yusuf. Suatu pengelolaan risiko yang sempurna. Proses manajemen risiko yang dterapkan Yusuf melalui tahapan pemahaman risiko, evaluasi dan pengukuran serta pengelolaan risiko.

\section{Teh}

Menurut Dirjen Perkebunan Kementan RI (2011:13) tanaman teh (Camellia Sinensis) merupakan tanaman yang menyegarkan dan menyehatkan. produk teh di Indonesia dibedakan atas teh hitam dan teh hijau. Perbedaan kedua jenis pengolahan tersebut disebabkan oleh perbedaan cara pengolahan dan peralatan yang dipergunakan. Proses pengolahan teh hitam memerlukan proses fermentasi yang cukup, sedangkan teh hijau tidak memerlukan fermentasi sama sekali. Fermentasi teh hitam memerlukan waktu lama (16-20 jam) dengan suhu rendah $25^{\circ}-30^{\circ} \mathrm{C}$, sebaliknya pada proses pengolahan teh hijau hanya memerlukan waktu pendek (6-7 menit) dengan suhu tinggi $90^{\circ}-100^{\circ} \mathrm{C}$.

Menurut IHT PTPN VIII (2011:20) Produk hilir teh mempunyai beragam kemasan. Kemasan memiliki kegunaan untuk mempertahankan rasa dan aroma teh, serta untuk mengawetkan atau memperpanjang waktu pakai. Produk hilir teh dan kemasan yang umum dipakai, antara lain :

1. Teh celup (tea bags)

2. Teh seduh

3. Teh instan (Instant tea)

4. Teh siap saji (ready to drink tea)

\section{Risiko}

Menurut Djohanputro (2008:3233) bahwa pada dasarnya risiko adalah sebagai ketidakpastian yang telah diketahui tingkat probabilitas kejadiannya. Pengertian lain risiko adalah ketidakpastian yang dikuantitaskan yang dapat menyebabkan kerugian atau kehilangan. Menurut Muslich (2007:5) risiko operasional mempunyai ruang lingkup yang mencakup risiko kerugian yang disebabkan oleh proses internal, kesalahan sumberdaya manusia perusahaan, kerusakan atau kesalahan sistem, kerugian yang disebabkan kejadian dari luar perusahaan, dan 
kerugian karena pelanggaran hukum atau peraturan perusahaan. Djohanputro (2008:43) menyatakan bahwa manajemen risiko korporat atau ERM (enterprise risk management) merupakan proses terstruktur dan sistematis dalam mengidentifikasi, mengukur, mengembangkan memetakan, penanganan risiko, dan dalam memonitor dan mengendalikan implementasi penanganan risiko. Secara menyeluruh proses manajemen risiko korporat dijelaskan pada Gambar 1.

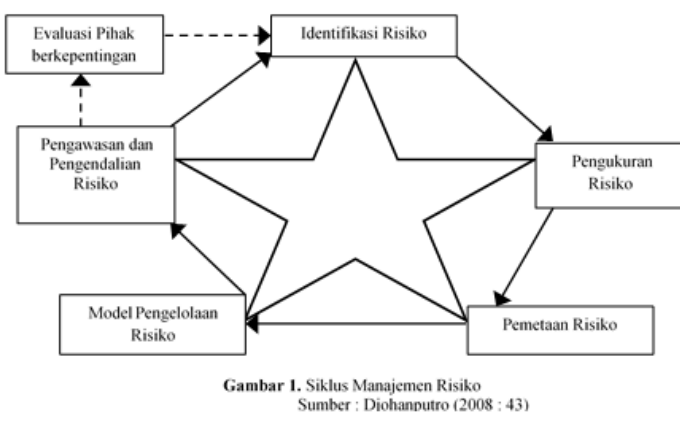

\section{Pemasaran}

Menurut Kotler dan Ketler (2009:5) pemasaran (marketing) adalah mengidentifikasi dan memenuhi kebutuhan manusia dan sosial. Salah satu definisi yang baik dan singkat dari pemasaran adalah "memenuhi kebutuhan dengan cara yang menguntungkan". Perusahaan yang menjual barang dan jasa untuk bisnis seiring menghadapi pembeli profesional yang terlatih dan dibekali informasi yang cukup, yang mengevaluasi penawaran yang kompetitif. Menurut Kotler dan Ketler (2009:19) konsep pemasaran beranggapan bahwa kunci untuk mencapai tujuan organisasi adalah menjadi lebih efektif daripada pesaing dalam menciptakan, menghantarkan dan mengomunikasikan nilai pelanggan yang lebih baik kepada pasar sasaran yang dipilih.

\section{METODE PENELITIAN}

\section{Lokasi dan Waktu Penelitian}

Penelitian ini dilaksanakan di IHT PTPN VIII, Cibiru, Bandung, Jawa Barat. Penelitian dan pengumpulan data ini dilakukan mulai bulan April - Juni 2015.

\section{Jenis dan Sumber Data}

Data yang digunakan dalam penelitian ini berupa data primer dan sekunder, yang bersifat data kuantitatif dan kualitatif. Data primer diperoleh dari pelaksanaan aktivitas pemasaran, serta informan terkait untuk mengetahui upaya perusahaan menghadapi kendala yang dihadapi IHT PTPN VIII. Data sekunder diperoleh melalui penelusuran berbagai dokumen tertulis IHT PTPN VIII, Kementerian Pertanian RI, serta beberapa penelitian terdahulu yang menjadi bahan rujukan bagi penelitian ini. Jenis data kuantitatif yang digunakan ialah data jumlah penjualan produk, harga produk, dan laporan keuangan IHT PTPN VIII berupa laporan biaya penjualan teh celup hijau Walini dengan kurun waktu Januari 2013 hingga Desember 2014.

\section{Metode Pengumpulan Data}

Pengumpulan data dalam penelitian ini menggunakan metode wawancara, pengamatan langsung (observasi), dan studi dokumen. Wawancara dilakukan dengan berkomunikasi dan bertanya kepada informan yang bekerja di unit pemasaran. Observasi dilakukan dengan cara mengamati atau melihat objek yang diidentifikasi.

Adapun yang menjadi informan dalam penelitian ini, yaitu : Sekertaris Manajer Pemasaran IHT, Kepala 
Bagian Penjualan dan Distribusi, Kepala Bagian Produksi, Kepala Bagian Promosi, Bagian Tata Buku Induk.

\section{Metode Pengolahan dan Analisis Data}

Data yang telah diperoleh selanjutnya dilakukan pengolahan data dengan bantuan Microsoft Excel. Pengolahan data terdiri dari tabulasi data dan klasifikasi data yang digunakan untuk analisis kualitatif dan kuantitatif. Analisis kualitatif dilakukan dengan pendekatan deskriptif yang digunakan untuk menjawab tujuan penelitian yang pertama dan ketiga. Analisis kuantitatif dengan metode Z-Score dan metode Value at Risk untuk mengetahui dampak risiko. Data yang digunakan adalah data arus produk (stock opname) dan penjualan teh celup hijau Walini.

1. Rumus yang digunakan untuk menghitung rata-rata penurunan penjualan produk teh Walini adalah :

$$
\bar{x}=\frac{\sum_{i=1}^{n} x i}{n}
$$

$\bar{x} \quad=$ Nilai rata-rata sisa produk teh celup hijau Walini Tahun 20132014

$x i=$ Nilai sisa produk per periode teh celup hijau Walini selama tahun 2013- 2014

$\mathrm{n} \quad=24$ periode $(24$ bulan dari total 2 tahun penjualan)

2. Menghitung nilai standar deviasi dari kejadian berisiko

$$
S=\sqrt{\frac{\sum_{i=1}^{n}(x i-\bar{x})^{2}}{n-1}}
$$

$\mathrm{S}=$ Standar deviasi dari sisa produk teh celup hijau Walini selama tahun 2013-2014

$x i=$ Nilai per periode sisa produk teh celup hijau Walini selama tahun 2013- 2014.

$\bar{x}=$ Nilai rata-rata dari sisa produk teh celup hijau Walini selama tahun 2013-2014

$\mathrm{n} \quad=24$ periode ( 24 bulan dari total 2 tahun penjualan).

3. Menghitung nilai Z-Score

Dimana :

$$
Z=\frac{x-\bar{x}}{S}
$$

$\mathrm{Z}=$ Nilai $z$-score dari sisa produk teh celup hijau Walini selama tahun 2013 - 2014

$\mathrm{S}=$ Standar deviasi dari sisa produk teh celup hijau Walini selama tahun 2013-2014

$x=$ Nilai per periode sisa produk teh celup hijau Walini selama tahun 2013- 2014

$x=$ Nilai rata-rata sisa produk teh celup hijau Walini selama tahun 20132014.

4. Mencari Probabilitas terjadinya Risiko Pemasaran

Menurut Kountur (2008:101) setelah nilai $z$-score dari penjualan teh Walini diketahui, selanjutnya dapat dicari probabilitas terjadinya risiko operasional pemasaran yang diperoleh dari tabel distribusi $\mathrm{z}$ (normal) sehingga dapat diketahui berapa persen kemungkinan yang dicari.

5. Mengukur Dampak Risiko

$$
\boldsymbol{V a R}=\overline{\boldsymbol{x}}+\boldsymbol{z}\left(\frac{s}{\sqrt{n}}\right)
$$

VaR = Dampak kerugian yang ditimbulkan oleh kejadian berisiko 
operasional pemasaran teh celup hijau (Rp).

$\bar{x}=$ Nilai Rata-rata kerugian akibat kejadian berisiko operasional pemasaran tehcelup hijau di IHT PTPN VIII

$z \quad=$ Nilai $\mathrm{z}$ yang diambil dari tabel distribusi normal dengan ( $\alpha=5 \%)$.

$\mathrm{S}=$ Standar deviasi dari sisa produk teh celup hijau Walini.

$n \quad$ = Banyaknya kejadian berisiko operasional pemasaran teh celup hijau Walini.

\section{Status Risiko}

\section{Status Risiko $=$ Probabilitas $\mathrm{x}$ Dampak}

7. Pemetaan Risiko

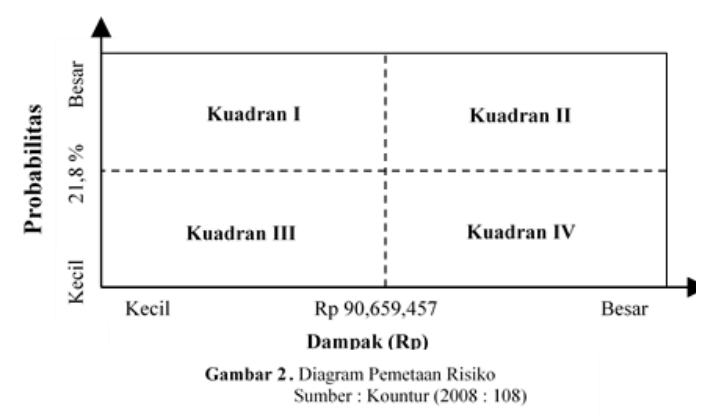

8. Strategi Penanganan Risiko

- Strategi Preventif dilakukan apabila probabilitas risiko besar, yaitu pada kuadran risiko I dan II. Strategi preventif akan membuat risiko-risiko berada pada kuadran I bergeser ke kuadran III dan risiko-risiko yang berada pada kuadran II bergeser ke kuadran IV.

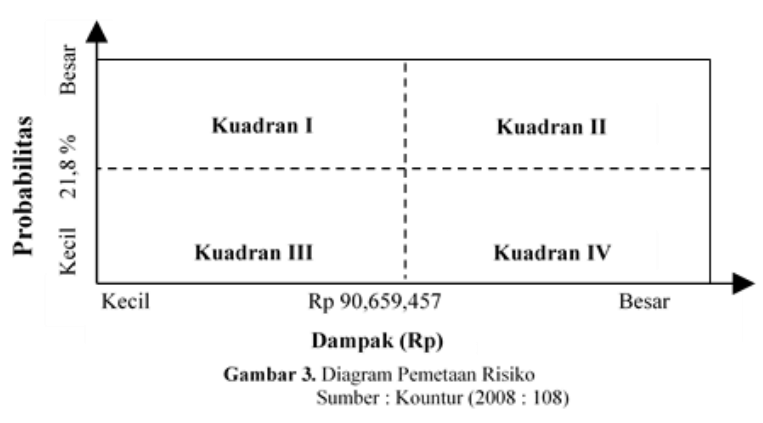

- Strategi mitigasi dilakukan untuk menangani risiko yang memiliki dampak yang sangat besar. Adapun cara yang dilakukan pada semua risiko yang berada pada kuadran II dan IV dapat bergeser ke kuadran I, dan ke kuadran III. Bentuk penanganan dapat dilakukan dengan diversifikasi penggabungan usaha, dan

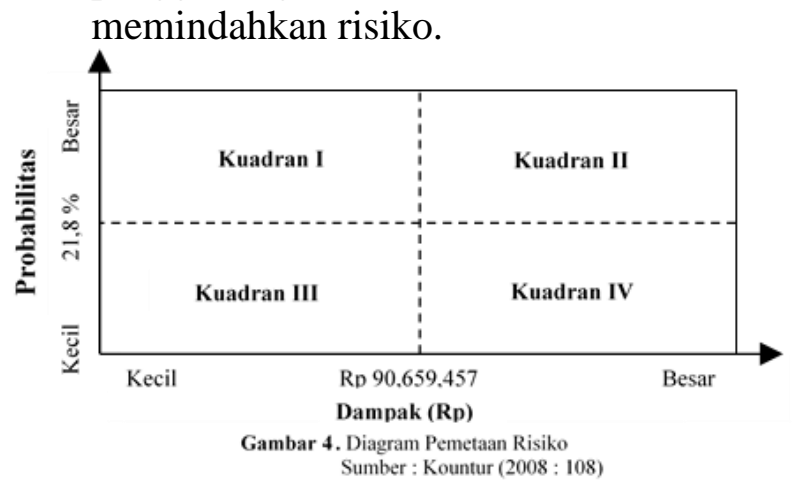

HASIL PENELITIAN

\section{Identifikasi Risiko}

Risiko diidentifikasi melalui beberapa cara : (1) data historis IHT PTPN VIII dalam laporan manajemen tahun 2013 dan 2014, (2) pemaparan dari pihak perusahaan yang langsung menangani di bidang tersebut dan (3) mengamati aktivitas operasional pemasaran secara langsung. Risikorisiko yang teridentifikasi dapat dikelompokkan menjadi tiga bagian, 
yaitu: sumberdaya manusia (SDM), sistem kerjasama, dan proses penjualan.

\begin{tabular}{|l|l|l|}
\hline $\begin{array}{l}\text { Sumber } \\
\text { Risiko }\end{array}$ & $\begin{array}{l}\text { Indikator } \\
\text { Risiko }\end{array}$ & $\begin{array}{l}\text { Kejadian } \\
\text { yang } \\
\text { merugikan }\end{array}$ \\
\hline & & $\begin{array}{l}\text { Faktur PO } \\
\text { yang tertukar }\end{array}$ \\
\cline { 3 - 3 } Proses & $\begin{array}{l}\text { Stagnasi pada } \\
\text { penjualan di } \\
\text { beberapa } \\
\text { market }\end{array}$ \\
\cline { 3 - 4 } Penjualan & $\begin{array}{l}\text { Kegagalan } \\
\text { Target }\end{array}$ & $\begin{array}{l}\text { informasa } \\
\text { penyajian teh } \\
\text { pada saat } \\
\text { pameran }\end{array}$ \\
\cline { 3 - 4 } & & $\begin{array}{l}\text { Terbatasnya } \\
\text { kendaraan } \\
\text { distribusi } \\
\text { yang dimiliki } \\
\text { IHT }\end{array}$ \\
\hline
\end{tabular}

\section{SDM}

Sumberdaya manusia dapat menjadi sebuah risiko yang menyebabkan terjadinya kerugian bagi perusahaan Identifikasi mengenai risiko

\begin{tabular}{|l|l|l|}
\hline $\begin{array}{l}\text { Sumber } \\
\text { Risiko }\end{array}$ & $\begin{array}{l}\text { Indikator } \\
\text { Risiko }\end{array}$ & $\begin{array}{l}\text { Kejadian } \\
\text { yang } \\
\text { merugikan }\end{array}$ \\
\hline & $\begin{array}{l}\text { Kerjasama } \\
\text { Distributor }\end{array}$ & $\begin{array}{l}\text { Distributor } \\
\text { telat } \\
\text { melakukan } \\
\text { pembayaran }\end{array}$ \\
\cline { 2 - 3 } $\begin{array}{l}\text { Sistem } \\
\text { Kerjasama }\end{array}$ & $\begin{array}{l}\text { Penumpukan } \\
\text { sisa Teh }\end{array}$ \\
& $\begin{array}{l}\text { Retur } \\
\text { Celup Hijau } \\
\text { Warang }\end{array}$ & $\begin{array}{l}\text { Walini di } \\
\text { gudang }\end{array}$ \\
\hline
\end{tabular}

operasional pada sumberdaya manusia unit pemaran IHT PTPN VIII dapat dilihat pada Tabel 2 .

Tabel 2. Daftar Risiko Sumberdaya Manusia (SDM)

\begin{tabular}{|l|l|l|}
\hline $\begin{array}{l}\text { Sumber } \\
\text { Risiko }\end{array}$ & $\begin{array}{l}\text { Indikator } \\
\text { Risiko }\end{array}$ & $\begin{array}{l}\text { Kejadian yang } \\
\text { merugikan }\end{array}$ \\
\hline \multirow{3}{*}{ SDM } & & $\begin{array}{l}\text { Intensitas } \\
\text { Karyawan } \\
\text { Harian Lepas } \\
\text { (KHL) salesman } \\
\text { yang keluar } \\
\text { cukup tinggi }\end{array}$ \\
\cline { 3 - 4 } & Kegawai & $\begin{array}{l}\text { Kelalaian dalam } \\
\text { melakukan } \\
\text { promosi sosial } \\
\text { media. }\end{array}$ \\
\cline { 3 - 4 } & $\begin{array}{l}\text { Penurunan } \\
\text { penjualan pada } \\
\text { modern outlet } \\
\text { dan traditional } \\
\text { outlet }\end{array}$ \\
\cline { 3 - 4 } & $\begin{array}{l}\text { Kesalahan dalam } \\
\text { memilih } \\
\text { distributor }\end{array}$ \\
\hline
\end{tabular}

Kerjasama

Risiko sistem Kerjasama merupakan potensi penyimpangan dari hasil yang diharapkan pada kegiatan pemasaran di IHT PTPN VIII.Identifikasi risiko sistem kerjasama produk teh celup hijau Walini terdapat pada Tabel 3.

Tabel 3. Daftar Risiko Sistem

Kerjasama

\section{Proses Penjualan}

Risiko proses penjualan adalah risiko mengenai potensi penyimpangan dari hasil yang diharapkan pada proses penjualan karena adanya penyimpangan atau kesalahan dalam kombinasi risiko (SDM dan sistem) dan eksternal perusahaan. Berikut identifikasi pada risiko operasional yang terdapat pada proses penjualan pada Tabel 4.

Tabel 4. Daftar Risiko Proses Penjualan

Analisis Nilai Standar atau Z-Score

Hasil perhitungan probabilitas risiko operasional dihitung dengan 
menggunakan metode $z$-score. Hasil perhitungan tersebut menunjukkan besar kemungkinan terjadinya risikorisiko tersebut pada operasional pemasaran teh celup hijau Walini di IHT PTPN VIII sebagaimana dapat dilihat pada Tabel 5 .

Tabel 5. Tingkat Probabilitas Sumber Risiko Operasional Pemasaran Sumber : Data Primer, 2015 (Diolah)

\begin{tabular}{|l|l|l|l|}
\hline N & $\begin{array}{l}\text { Sumber } \\
\text { o. }\end{array}$ & $\begin{array}{l}\text { Z- } \\
\text { Risiko }\end{array}$ & $\begin{array}{l}\text { Probabi } \\
\text { litas } \\
(\%)\end{array}$ \\
\hline 1. & $\begin{array}{l}\text { Risiko } \\
\text { Sumberday } \\
\text { a Manusia } \\
\text { (SDM) }\end{array}$ & $-1,02$ & 15,4 \\
\hline 2. & $\begin{array}{l}\text { Risiko } \\
\text { Sistem } \\
\text { Kerjasama }\end{array}$ & $-0,60$ & 27,4 \\
\hline 3. & $\begin{array}{l}\text { Risiko } \\
\text { Proses } \\
\text { Penjualan }\end{array}$ & $-0,72$ & 23,6 \\
\hline
\end{tabular}

Dari perhitungan $z$-score nilai probabilitas tertinggi dari ketiga penyebab risiko operasional pemasaran (sumberdaya manusia, sistem, dan proses penjualan) adalah pada risiko sistem kerjasama $(27,4)$ dan nilai probabilitas terendah adalah risiko sumberdaya manusia $(15,4)$. Adapun tingkat saldo akhir atau sisa produk teh celup hijau Walini yang ditoleransi adalah sebesar 25 persen atau $146.21 \mathrm{~kg}$ pada penjualan yang dilakukan setiap bulannya oleh IHT PTPN VIII. Nilai z -0,60 pada tabel z menunjukkan nilai sebesar 0,274 . Nilai 0,274 menunjukkan sistem kerjasama memiliki risiko dengan tingkat probabilitas 27,4 persen, sebagai faktor penyebab tingkat sisa produk teh celup hijau Walini yang tidak terjual pada setiap penjualan di atas $146.21 \mathrm{~kg}$. Probabilitas terjadinya risiko sistem kerjasama menandakan usaha ini bergantung pada sistem setiap pelaksanaan di unit pemasaran teh celup hijau Walini.

Risiko terbesar kedua adalah risiko proses penjualan dengan nilai probabilitas sebesar 23.4 persen. Risiko proses ini terjadi mulai dari pengadaan barang pesanan yang tidak sesuai dengan pre-order, ketidaksesuaian tersebut dikarenakan faktur PO yang tertukar sehingga terkadang jumlah pemesanan terjadi kesalahan. Selain itu risiko pada proses terjadi pada penjualan yang mengalami stagnasi dibeberapa pasar karena pergantian vendor dari PT ATRI ke PT Multi Kreasi Inti pada tahun 2014, sehingga menyebabkan belum terjadi peningkatan penjualan sebagaimana yang diharapkan. Nilai probabilitas yang disebabkan oleh sumberdaya manusia (SDM) adalah 15,4 persen. Risiko sumberdaya manusia sendiri terjadi karena lalainya kinerja pegawai dalam melakukan promosi yang belum banyak dilakukan melalui media sosial, padahal banyak peluang pasar yang dapat diraih melalui penjualaan online. Selain berdasarkan ketiga faktor utama dalam risiko operasional, probabilitas risiko juga dapat dihitung berdasarkan risiko perkejadian dalam risiko SDM, sistem kerjasama dan proses penjualan teh celup hijau Walini pada Tabel 6 .

Tabel 6. Probabilitas Terjadinya Risiko Berdasarkan Risiko per Kejadian 


\begin{tabular}{|l|l|l|l|}
\hline No. & Risiko (Kejadian yang Merugikan) & Z-Score & Probabilitas (\%) \\
\hline Risiko Sumberdaya Manusia & & \\
\hline 1 & Kelalaian Penjualan & 1,50 & 6.70 \\
\hline 2 & Kelalaian Promosi sosial media & $-0,35$ & 36.30 \\
\hline 3 & Kesalahan memilih distributor & $-1,10$ & 13.60 \\
\hline Risiko Sistem Kerjasama & & \\
\hline 1 & $\begin{array}{l}\text { Distributor terlambat melakukan pembayara } \\
\text { hutang }\end{array}$ & $-0,47$ & 31.90 \\
\hline 2 & Pengembalian produk (Retur barang) & 0,07 & 47.20 \\
\hline Risiko Proses Penjualan & & \\
\hline 1 & Stagnasi Produk & $-0,03$ & 48.80 \\
\hline 2 & Kurangnya informasi penyajian teh & 0,28 & 39.00 \\
\hline 3 & Terbatasnya kendaraan & $-0,40$ & 34.50 \\
\hline
\end{tabular}

Sumber : Data Primer, 2015 (Diolah)

Pada Tabel 6 dapat dilihat bahwa probabilitas risiko per kejadian pada stagnasi produk, pengembalian produk (retur barang), kurangnya informasi penyajian teh, kelalaian promosi sosial media merupakan kejadian yang memiliki probabilitas terbesar. Kemungkinan sisa teh celup hijau Walini di atas 25 persen yang disebabkan stagnasi produk adalah sebesar 48.80 persen, risiko ini tergolong besar karena memang pergantian vendor distributor sangatlah berpengaruh terhadap aktivitas listing pada penjualan di pasar-pasar modern, selain itu persaingan harga juga menjadi sebuah tantangan dalam pasar dagang teh celup hijau yang begitu kompetitif. Sehingga stagnasi produk teh celup hijau Walini sangat terasa ketika penyalur barang mengalami hambatan dalam peningkatan selling in di berbagai outlet.

\section{Analisis Value at Risk (VaR)}

Perhitungan dampak risiko yang terjadi pada pemasaran teh celup hijau Walini di IHT PTPN VIII dilakukan dengan menggunakan metode Value at Risk (VaR). Perhitungan VaR menggunakan tingkat keyakinan 95 persen dan 5 persen sisanya adalah galat atau error. Data yang digunakan dalam perhitungan ini adalah laporan penjualan terhadap daya serap produk teh celup hijau Walini di setiap bulannya pada tahun 2013 dan 2014. Perbandingan dampak risiko operasional pada pemasaran teh celup hijau Walini dapat dilihat pada Tabel 7.

Tabel 7. Dampak Risiko Operasional Pemasaran

\begin{tabular}{|l|l|l|}
\hline No. & Sumber Risiko & Dampak (Rp) \\
\hline 1. & $\begin{array}{l}\text { Risiko Sumberdaya } \\
\text { Manusia (SDM) }\end{array}$ & $102,615,683$ \\
\hline 2. & $\begin{array}{l}\text { Risiko Sistem } \\
\text { Kerjasama }\end{array}$ & $90,926,024$ \\
\hline 3. & $\begin{array}{l}\text { Risiko Proses } \\
\text { Penjualan }\end{array}$ & $78,436,664$ \\
\hline
\end{tabular}

Pada tabel 7 dijelaskan bahwa dampak kerugian terbesar terjadi pada risiko 
sumberdaya manusia dengan kerugian sebesar Rp 102.615.683, kemudian risiko sistem kerjasama sebesar $\mathrm{Rp}$ 90,926,024, dan terakhir diikuti oleh risiko proses penjualan dengan kerugian sebesar $\mathrm{Rp}$ 78.436.664. Dampak atau kerugian terbesar terjadi pada risiko sumberdaya manusia. Hal ini menunjukkan bahwa jika terjadi risiko SDM, maka perusahaan akan mengalami kerugian terbesar jika dibandingkan dengan terjadi risiko lainnya. Besarnya dampak yang disebabkan oleh risiko SDM adalah sebesar Rp 102,615,683, dengan tingkat keyakinan dipakai adalah 95 persen. Hal ini berarti dengan tingkat keyakinan 95 persen, kerugian yang diderita maksimal Rp 102,615,683, namun ada 5 persen kemungkinan lebih besar dari Rp 102,615,683. Oleh karena itu bisa dinyatakan dengan $\mathrm{VaR}$ Rp102,615,683 at 5 persen. Dampak risiko juga dapat dihitung berdasarkan risiko per kejadian dalam risiko sumberdaya manusia, sistem kerjasama dan proses penjualan pada pemasaran teh celup hijau Walini pada Tabel 8.

Tabel 8. Dampak Terjadinya Risiko Berdasarkan Risiko per Kejadian

\begin{tabular}{|l|l|l|}
\hline No. & Risiko (Kejadian yang Merugikan) & Dampak (Rp) \\
\hline \multicolumn{2}{|l|}{ Risiko Sumberdaya Manusia } & \\
\hline 1 & Kelalaian Penjualan & $69,115,676$ \\
\hline 2 & Kelalaian Promosi & $127,458,211$ \\
\hline 3 & Kesalahan memilih distributor & $203,448,914$ \\
\hline Risiko Sistem Kerjasama & \\
\hline 4 & Distributor terlambat melakukan pembayaran hutang & $113,984,158$ \\
\hline 5 & Pengembalian produk (Retur Barang) & $161,928,496$ \\
\hline Risiko Proses Penjualan & \\
\hline 6 & Terbatasnya kendaraan & $69,222,999$ \\
\hline 7 & Stagnasi Produk & $64,704,214$ \\
\hline 8 & Kurangnya informasi penyajian teh & $69,998,022$ \\
\hline
\end{tabular}

Sumber : Data Primer, 2015 (Diolah)

\section{Status Risiko}

Proses selanjutnya yang harus dilakukan adalah pemetaan risiko yang dilakukan dengan dua cara, yaitu : menentukan status risiko dan pemetaan risiko. Status risiko operasional dapat dilihat pada Tabel 9.

Tabel 9. Perhitungan Status Risiko Operasional Pemasaran Berdasarkan Per Kejadian

\begin{tabular}{|l|l|l|l|l|}
\hline No. & $\begin{array}{l}\text { Risiko (Kejaadian yang } \\
\text { Merugikan }\end{array}$ & $\begin{array}{l}\text { Probabilita } \\
\text { s }(\%)\end{array}$ & $\begin{array}{l}\text { Dampak } \\
(\mathrm{Rp})\end{array}$ & Status \\
\hline Risiko Sumberdaya Manusia & & & \\
\hline 1 & Kelalaian Penjualan & 6.70 & $69,115,676$ & $463,075,028$ \\
\hline 2 & Kelalaian Promosi & 36.30 & $127,458,211$ & $\begin{array}{l}4,626,733,05 \\
0\end{array}$ \\
\hline 3 & $\begin{array}{l}\text { Kesalahan memilih } \\
\text { distributor }\end{array}$ & 13.60 & $203,448,914$ & $\begin{array}{l}2,766,905,22 \\
7\end{array}$ \\
\hline
\end{tabular}




\begin{tabular}{|l|l|l|l|l|}
\hline \multicolumn{2}{|l|}{ Risiko Sistem Kerjasama } & & & - \\
\hline 4 & $\begin{array}{l}\text { Distributor terlambat } \\
\text { melakukan pembayaran } \\
\text { hutang }\end{array}$ & 31.90 & $161,928,496$ & $\begin{array}{l}5,181,711,86 \\
8\end{array}$ \\
\hline 5 & Pengembalian produk & 47.20 & $113,984,158$ & $\begin{array}{l}5,380,052,27 \\
6\end{array}$ \\
\hline \multicolumn{2}{|l|}{ Risiko Proses Penjualan } & & & - \\
\hline 6 & $\begin{array}{l}\text { Kurangnya informasi } \\
\text { penyajian teh }\end{array}$ & 39.00 & $69,222,999$ & $\begin{array}{l}2,699,696,96 \\
2\end{array}$ \\
\hline 7 & $\begin{array}{l}\text { Stagnasi Produk } \\
8\end{array}$ & 48.80 & $64,704,214$ & $\begin{array}{l}3,157,565,65 \\
9\end{array}$ \\
\hline 8 & Terbatasnya kendaraan & 34.50 & $69,998,022$ & $\begin{array}{l}2,414,931,76 \\
5\end{array}$ \\
\hline
\end{tabular}

Sumber : Data Primer, 2015 (Diolah)

Status risiko tertinggi terdapat pada risiko sistem kerjasama yaitu pada risiko pengembalian produk dengan nilai sebesar Rp 5,380,052,276 kemudian disusul oleh risiko distributor yang terlambat melakukan pembayaran yang memiliki status terbesar Rp 5,181,711,868. Posisi ketiga status risiko ditempati oleh kelalaian promosi yang memiliki status sebesar Rp 4,626,733,050. Pengembalian produk, distributor telat melakukan pembayaran, dan kelalaian promosi memiliki nilai status tinggi disebabkan oleh nilai probabilitas dan dampak yang besar.

\section{Pemetaan Risiko}

Peta risiko merupakan gambaran tentang posisi risiko pada suatu peta yang ditentukan dari rata-rata probabilitas dan dampak yang terjadi pada pemasaran teh celup hijau Walini di IHT PTPN VIII. Berdasarkan pada Gambar 4dapat dilihat bahwa risiko yang dipetakan per kejadian menyebar ke dalam empat kuadran seperti halnya risiko berdasarkan ketiga faktor penyebab risiko operasional. Risiko yang berada kuadran I, II, III, IV dapat dilihat pada Gambar 3.

\begin{tabular}{|l|l|}
\hline $\begin{array}{l}\text { Terbatasnya kendaraan } \\
\text { stagnasi produk kurabgnya } \\
\text { informasi penyajian teh }\end{array}$ & $\begin{array}{l}\text { Kesalahan memilih } \\
\text { distributor }\end{array}$ \\
\hline Kelalaiaan Penjualan & \\
\hline
\end{tabular}

Rp 90,659,457

\section{Strategi Penanganan Risiko Operasional Pemasaran}

Penanganan risiko yang paling tepat berdasarkan hasil pemetaan sumber risiko untuk dilaksanakan, yaitu : strategi preventif dan mitigasi. 


\section{Strategi Preventif}

Strategi preventif untuk pemetaan pada kuadran I ntara lain : a). meningkatkan awareness produk terutama diwilayah Jawa Barat dan Jabodetabek melalui kegiatan Sales Promo, Sponsorship, kegiatan Below The Line, serta promo di berbagai media cetak, radio, dan brosur, b). Menambah listing produk dibeberapa market sesuai anggaran yang tersedia (Giant, Lottemart, Carrefour, HariHari, Rajawali Mart, Pertamina Bright, Watson). c). Promosi sendiri harus lebih digencarkan melalui website khusus untuk teh Walini, media sosial, seperti facebook, twitter, instagram dan path, penggunaan media tersebut harus dilakukan setiap hari dan jangan hanya sesekali saja. d) Meningkatkan kerjasama dengan moda transportasi massal (Cipaganti Travel). Sedangkan pada kuadran II dapat dilakukan dengan penanganan membuat sistem pengorganisasian dalam pembuatan program promosi yang bermula dari rekrutmen tenaga promosi yang memiliki keahlian dalam desain komunikasi visual, pembuatan program deadline dari tiap program dan dibutuhkan penghargaan bagi promotor yang dapat menjual produk teh celup hijau Walini melampaui dari target yang ditentukan. Pencatatan akuntansi sangat penting untuk membuat grafik penjualan pada setiap penjualan konsinyasi, agar dikemudian hari tidak terjadi pengembalian barang yang begitu besar. Barang yang telah kembali bisa juga dimanfaatkan dalam bentuk penjualan dengan memberikan potongan harga 20-25 persen dari harga normal.

\section{Strategi Mitigasi}

Strategi mitigasi dilakukan untuk menangani sumber risiko operasional pemasaran yang berada di kuadran II dan IV. Strategi mitigasi yang dilakukan untuk menangani kelalaian promosi bisa dilakukan dengan cara Socialpreneur merupakan suatu konsep kewirausahaan yang menggabungkan nilai-nilai sosial untuk meningkatkan keuntungan tidak hanya yang didapat perusahaan, melainkan orang banyak. Detect dan monitor terhadap kinerja pegawai dengan proporsional dan tidak berlebihan. Sumberdaya manusia pada unit pemasaran teh celup hijau Walini dilakukan dengan melakukan sistem kontrak (outsourcing) untuk posisi promosi. Kontrak yang dilakukan sesuai kesepakatan pihak IHT PTPN VIII dan tenaga outsourcing. Penambahan personil juga diperlukan untuk manajer pemasaran, tenaga promosi dan team spreading. untuk menangani distributor yang telat melakukan pembayaran dengan membuat bank garansi. Bank garansi merupakan suatu bentuk jaminan berupa pembayaran uang oleh distributor kepada suatu bank, berdasarkan kesepakatan antara pihak distributor dan IHT PTPN VIII. Dana jaminan ini dapat diambil oleh IHT PTPN VIII, jika distributor tidak membayar uang atas pengambilan barang berupa teh celup hijau Walini.

Strategi mitigasi yang dilakukan untuk kesalahan dalam memilih distributor ialah melalui selective hedging atau suatu transaksi atas dasar fakta di pasar yang pernah dilakukan sebelumnya dan pada masa akan datang akan yang memiliki variasi pada volume dan eksekusi order. Bentuk diversifikasi usaha bisa dilakukan dengan membuka outlet secara merata dengan kepemilikan sendiri dan tidak terikat dengan 
kepemilikan orang lain. Sehingga dengan usaha seperti itu, akan memperkecil biaya operasional dan kontrol terhadap produk dapat berjalan dengan baik.

\section{KESIMPULAN DAN SARAN}

\section{Kesimpulan}

1. Risiko-risiko yang teridentifikasi pada unit pemasaran IHT PTPN VIII untuk produk teh celup hijau Walini dapat dikelompokkan berdasarkan penyebab risiko operasional yaitu risiko sumberdaya manusia, sistem kerjasama, dan proses penjualan.

2. Berdasarkan metode nilai standar didapatkan nilai tertinggi dari ketiga penyebab risiko operasional adalah risiko sistem kerjasama (26.4\%) dan nilai probabilitas terendah adalah risiko sumberdaya manusia $(15.4 \%)$. Probabilitas risiko per kejadian : stagnasi produk, distributor telat melakukan pembayaran, kurangnya informasi penyajian teh, kelalaian promosi memilliki probabilitas terbesar. Risiko sumberdaya manusia memiliki dampak atau kerugian terbesar dengan nilai $\mathrm{Rp}$ 102,615,683, sedangkan kerugian terkecil dialami oleh proses dengan nilai $\mathrm{Rp} 78,436,664$. Dampak tersebut dapat dihitung dengan menggunakan metode Value at Risk (VaR).

3. Alternatif penanganan risiko operasional yang terjadi di IHT PTPN VIII berdasarkan hasil pemetaan sumber risiko yang ada dalam usaha pemasaran teh celup hijau Walini dilakukan dalam dua strategi penanganan, yaitu preventif dan mitigasi.

\section{Saran}

1. Berdasarkan penelitian, diketahui bahwa risiko sumberdaya manusia memiliki dampak yang besar. Apabila risiko ini terjadi maka sangat mengganggu pencapaian perusahaan. Oleh karena itu dibutuhkan penerapan Good Corporate Governance (GCG) atau tata kelola perusahaan yang baik berlandaskan kinerja pegawai yang baik dalam menanggulangi risiko.

2. Penanganan risiko harus diikuti dengan semangat perusahaan dalam pengembangan secara terpadu dan komprehensif. Terpadu berarti semua pembangunan harus terlaksana seiring dan seirama secara proporsional. Sedangkan komprehensif berarti tidak hanya memperhatikan aspek keberhasilan dalam meraih laba, tetapi juga moral spiritual dan mental emosional harus dimiliki pada setiap karyawan.

3. Sebaiknya dilakukan sebuah penelitian lanjutan untuk menghitung nilai risiko dan keuntungan yang diharapkan dari masing-masing risiko. Sehingga dapat dibandingkan antara keuntungan dan kerugian yang diharapkan dari risiko suatu kegiatan. 
(Jakarta : Kementerian

Pertanian RI, 2011)

\section{DAFTAR PUSTAKA}

Al-Qur'an Cordoba. Yusuf AS Mentakwilkan Mimpi Raja dalam Ibnul Asir Al-Jazari. (Bandung : Cordoba, 2015)

Annual Report."Mengoptimalkan Potensi Perusahaan". (Jawa Barat, Bandung : PT Perkebunan Nusantara VIII, 2013)

Andessa. "Analisis Risiko Produksi Jamur Tiram Putih Pada DD. Mushroom di Kecamatan Ciawi Kabupaten Bogor, Provinsi Jawa Barat. [Skripsi]. (Jawa Barat, IPB Bogor : Fakultas Ekonomi dan Manajemen, Departemen Agribisnis, 2014)

Balittri. Mengenal 4 Macam Jenis Tehhttp://balittri.litbang.pertan ian.go.id/index.php/componen t/content/article/49infotekno/159-mengenal-4macam-jenis-teh. 2012. 1 hlmn. 25 April 2015. Pk. 07.08 WIB

Chanrilo, Welfrin. "Analisis Risiko Usaha Diversifikasi Anggrek Dendrobium Pada Permata Anggrek Di Kota Bogor, Provinsi Jawa Barat". [Skripsi]. (Jawa Barat, IPB Bogor : Fakultas Ekonomi dan Manajemen, Departemen Agribisnis, 2011)

Direktorat Jenderal Perkebunan. "Profil Komoditi Teh".
Djohanputro. "Manajemen Risiko Korporat". (Jawa Barat, Bogor : PPM Manajemen, 2008)

Fakultas Sains dan Teknologi. "Pedoman Penulisan Skripsi Jurusan Sosial Ekonomi Pertanian/Agribisnis".

(Jakarta : UIN Syarif Hidayatullah Jakarta, 2006/1427H)

IHT PTPN VIII. "Profil Teh Walini". (Jawa Barat, Bandung : 2011).

IHT PTPN VIII. "Laporan Manajemen (LM) IHT PTPN VIII Tahun 2013, 2014, 2015”. (Jawa Barat, Bandung : IHT PTPN VIII, 2011)

Irawan, Yogie. Manajemen Risiko dalam Islam. http://www.pkskelapadua.com /01/manajemen-risiko-dalamislam.html. 2013. 1 Juli 2015. Pk. 11.48 WIB.

Kotler, P dan Ketler, P. "Manajemen Pemasaran Edisi 13 Jilid 1". Jakarta :Erlangga : Jakarta, 2008)

Kotler dkk. "Manajemen Pemasaran Perspektif Asia Buku 1". (Yogyakarta : Erlangga, 2000).

Kountur, R. "Mudah Memahami Manajemen Risiko Perusahaan". (Jakarta : PPM Manajemen,2008)

Muslich, Muhammad. "Manajemen Risiko Operasional Teori \& 
Praktik”.(Jakarta :PT Bumi

Aksara, 2007).

Purwitasari, Azizah. "Manajemen

Risiko Operasional

Pemasaran Benih Ikan Patin

PT Mitra Mina Nusantara Di

Kabupaten Bogor, Jawa

Barat”. [Skripsi]. (Jawa Barat,

IPB Bogor : Fakultas Ekonomi

dan Manajemen, Departemen

Agribisnis, 2011).

* Alamat Korespondensi:

riyadi.wastra@uinjkt.ac.id 
Jurnal Agribisnis, Vol. 12, No. 1, Juni 2018, [ 11 - 26 ]

ISSN : 1979-0058 